\title{
A METHOD FOR MEASURING TONE AND REFLEX CONSTRICTION OF THE CAPILLARIES, VENULES AND VEINS OF THE HUMAN HAND WITH THE RESULTS IN NORMAL AND DISEASED STATES
}

\author{
By RICHARD B. CAPPS \\ (From the Thorndike Memorial Laboratory, Second and Fourth Medical Services (Harvard), \\ Boston City Hospital, and the Department of Medicine, Harvard Medical School, Boston)
}

(Received for publication October 10, 1935)

During the past fifteen years considerable attention has been paid to the physiology of the capillary and venous side of the circulation. It is now believed by many workers that capillaries possess tone and that they are able to constrict and dilate actively in response to either local or nervous stimuli $(1,2,3,4)$. Although the veins have not been as thoroughly studied, there is considerable evidence indicating that in certain regions, notably the skin and the splanchnic area, a similar situation exists $(5,6)$. As a result of these advances in our knowledge, the true importance of the veins and capillaries in many circulatory phenomena is gradually being appreciated $(4,7,8)$.

In man there are relatively few methods of measuring the tone of these vessels and most of those available can be applied only to a very small area or to a single vessel. While investigating the blood flow in the hand (9), using the plethysmographic method of Hewlett and Van Zwaluwenburg $(10,11)$ as modified by Freeman ${ }^{7}$ (12), a means was found for measuring tone and reflex vasoconstriction in the capillaries and veins of the whole hand. Because of the probable importance of such measurements in certain diseased states, the present study was undertaken.

Lewis (1) has shown by a variety of methods that the minute vessels of the hand actively constrict in response to adrenalin and cold, and actively dilate in response to heat and inadequate blood flow. He has also observed, as is common knowledge, that, grossly, the large veins of the hand and arm dilate with heat and constrict with cold. He found that the minute vessels of the arm are capable of withstanding a pressure of

1 I am indebted to Dr. N. E. Freeman of the Massachusetts General Hospital for generously providing me with the plans of his apparatus.
$100 \mathrm{~mm} . \mathrm{Hg}$ if previously constricted, and are able to contract actively against a pressure of 60 $\mathrm{mm} . \mathrm{Hg}$.

It is known that when a blood pressure cuff is applied to the forearm at a pressure above that in the veins but below that in the arteries, the volume of the hand is found to increase at a rapid rate for 15 to 30 seconds and then much more slowly for an indefinite period of time. Drury and Jones (13) and Lewis (1) state, as seems obvious, that the first phase is due to collection of blood in the minute vessels and veins, and ends when the pressure in them is equal to the cuff pressure. Lewis (14) has shown by direct measurement that the venous pressure under these circumstances equals the cuff pressure in 15 to 30 seconds. The second phase, they believe, is due either to stretching of the vessel walls or to overcoming the muscle tone present, and to the production of tissue fluid. Therefore, it can be assumed that the rapid initial increase in hand volume produced by a pressure cuff at the wrist is a measure of the additional quantity of blood present in the minute vessels and veins or of the increase in their capacity as a result of the increase in venous pressure.

The specific vessels involved in this increase in volume will depend on the cuff pressure and the previously existing pressure in different parts of the capillary-venous system. Landis (15) has found by direct measurements that the normal pressure in man in the venous end of the capillary loop varies between 6 and $19 \mathrm{~mm}$. Hg. During hyperemia, however, he found the pressure to be 42 to $51 \mathrm{~mm}$. Hg. It is therefore evident that a cuff pressure of 20 or $30 \mathrm{~mm}$. Hg will sometimes cause a rise in the intravascular pressure of the veins, venules and capillaries and at other times will affect the veins alone. Since it was not feasi- 
ble in this investigation to determine whether, in a given experiment, the pressure changes occurred in the veins alone or in the venules and capillaries as well, no attempt has been made to distinguish the type of vessels affected. For convenience, the term venous or veins should be understood to include the veins, venules and capillaries as the case demands, or in other words, those vessels in which the intravascular pressure has been changed.

In the course of an investigation when actual measurements of the increase in hand volume due to different cuff pressures were made, they were found to be fairly constant under controlled conditions (9). Furthermore, they showed characteristic variations with such factors as temperature. This suggested that the relationship of increase in volume to increase in cuff pressure, or in other words the relationship of the increment of venous volume to that of intravascular pressure, might be used to measure the elasticity and possibly the tone of the venous system of the hand. Clark (16) has actually made such determinations with a method similar to the one used in the present investigation. She concluded that elasticity increases with age. However, she did not make determinations in relation to temperature or other factors which might alter the tonus of the vessels.

It is not within the scope of this paper to discuss the difficult subjects of elasticity and tonus in smooth muscle. Only a few relevant facts will be mentioned. Evans (17) in a recent review of the subject, defines tonus as the "resistance to stretch." This definition has been followed throughout. ${ }^{2}$

Evans also states that it is generally agreed that cold increases and heat decreases the tone of smooth muscle. MacWilliams (18) and Kesson (19) have experimentally measured the elastic properties of mammalian smooth muscle taken from many sources, including arteries, in such a. way as to be applicable to the present study. They carried out experiments with both strips of

2 It is recognized that the term "tonus," as used in this paper, includes the resistance to stretch of not only the muscular elements, but also of the elastic tissue elements of the vessel walls. These two factors are separable only in those experiments where rapid reflex changes in tone occur, since nervous stimulation can only affect muscle tissue. muscle and intact hollow viscera. Measurements were made of the increase in length or volume in response to equal increments respectively of stretch or pressure. Relaxed muscle showed decreasing increments of stretch with increase in the stretching force. Contracted muscle showed increasing increments of stretch up to a maximum, and then decreasing increments as the stretching force was increased.

Application of these facts to the subject in hand results in the conclusion that, other factors being constant, the less the increment of hand volume with a given low cuff pressure, the greater must be the tonus of the veins providing that they are not rigid from disease. Furthermore, if we accept MacWilliams' and Kesson's findings, increasing the cuff pressure by equal amounts should give increasing increments of hand volume at first if the tone of the vessels is marked, and decreasing increments if the veins are relaxed. Findings of this nature were actually observed.

TABLE I

Normal subjects

\begin{tabular}{|c|c|c|c|c|c|c|c|c|}
\hline \multirow{4}{*}{$\begin{array}{c}\mathrm{Pa}- \\
\text { tient }\end{array}$} & \multirow{4}{*}{ Sex } & \multirow{4}{*}{ Age } & \multirow{4}{*}{$\begin{array}{l}\text { Hand } \\
\text { vol- } \\
\text { ume }\end{array}$} & \multicolumn{4}{|c|}{$\begin{array}{l}\text { Increment of hand volume obtained } \\
\text { by raising cuff pressure from } \\
0 \text { to } 20 \mathrm{~mm} . \mathrm{Hg}\end{array}$} & $\begin{array}{l}\text { Decrease } \\
\text { in volume } \\
\text { with } \\
\text { pinch. } \\
\text { Cuff pres- } \\
\text { sure } 20 \\
\text { mm. } \mathrm{Hg}\end{array}$ \\
\hline & & & & \multicolumn{3}{|c|}{ Without leg heater } & $\begin{array}{l}\text { With } \\
\text { leg }\end{array}$ & \multirow{3}{*}{$\begin{array}{c}\begin{array}{c}\text { Without } \\
\text { leg } \\
\text { heater }\end{array} \\
30^{\circ}\end{array}$} \\
\hline & & & & \multicolumn{4}{|c|}{ Temperature of plethysmograph $\left({ }^{\circ} \mathrm{C}.\right)$} & \\
\hline & & & & $23^{\circ}$ & $30^{\circ}$ & $42^{\circ}$ & $30^{\circ}$ & \\
\hline & & years & $c c$. & $\begin{array}{l}\text { cc. per } \\
\text { liter of } \\
\text { hand } \\
\text { volume }\end{array}$ & $\begin{array}{l}\text { cc. per } \\
\text { liter of } \\
\text { hand } \\
\text { volume }\end{array}$ & $\begin{array}{l}\text { cc. per } \\
\text { liter of } \\
\text { hand } \\
\text { volume }\end{array}$ & $\begin{array}{l}\text { cc. per } \\
\text { liter of } \\
\text { hand } \\
\text { volume }\end{array}$ & $\begin{array}{l}\text { cc. per } \\
\text { liter of } \\
\text { hand } \\
\text { volume }\end{array}$ \\
\hline $\begin{array}{l}\text { F.H. } \\
\text { G.B. } \\
\text { R.S. } \\
\text { G.T. } \\
\text { S.M. } \\
\text { E.F. }\end{array}$ & $\begin{array}{c}\mathrm{F} \\
\mathbf{M} \\
\mathrm{F} \\
\mathrm{F} \\
\mathrm{F} \\
\mathrm{M}\end{array}$ & $\begin{array}{l}28 \\
50 \\
36 \\
35 \\
18 \\
29\end{array}$ & $\begin{array}{l}260 \\
510 \\
220 \\
330 \\
200 \\
410\end{array}$ & $\begin{array}{l}2.1 \\
0.1 \\
2.7 \\
4.8 \\
1.9 \\
2.3\end{array}$ & $\begin{array}{r}7.3 \\
0.4 \\
8.0 \\
10.5 \\
3.8 \\
4.5\end{array}$ & $\begin{array}{l}4.2 \\
9.3 \\
6.8 \\
5.4 \\
3.0\end{array}$ & $\begin{array}{l}13.8 \\
10.8\end{array}$ & $\begin{array}{l}6.2 \\
0 \\
0.9 \\
1.0 \\
2.8 \\
3.0\end{array}$ \\
\hline
\end{tabular}

\section{METHOD}

The apparatus used has been fully described by Freeman (12) in his paper on the measurement of blood flow. Briefly, it consisted of an insulated plethysmograph large enough to hold the hand up to wrist. A special cuff made of dentists' rubber dam was attached to the wrist with rubber cement in such a way that practically no pressure was exerted on the veins. This was checked in every 
experiment by determining at a suitable time the least cuff pressure necessary to produce an increase in hand volume. Direct measurements of venous pressure showed that this was a reliable method if done when the veins were relaxed. The rubber dam covered the open end of the plethysmograph and was made water tight with a metal ring. In order to prevent bulging of the rubber a piece of thick felt was fitted around the wrist and held in place by two iris diaphragms. The plethysmograph was fitted with an electric stirrer, a thermometer and an electric heater, and filled with water nearly to the top. By air conduction through small pressure tubing, volume changes were transmitted to a $10 \mathrm{cc}$. Brodie's bellows which wrote, along with a time marker, on a smoked drum. Around the wrist just proximal to the ulnar styloid a blood pressure cuff one and one-half inch wide was placed. This was connected to a large pressure bottle and mercury manometer so that it could be suddenly inflated and deflated to any desired pressure. The Brodie's bellows was standardized before each experiment by putting $1,2,3$, and $4 \mathrm{cc}$. of air into the system and drawing a horizontal line representing each amount all around the kymograph paper. The total hand volume was determined by measuring the displacement volume in the plethysmograph. From this the volume changes were calculated for each liter of hand volume.

While carrying out experiments the patient was always horizontal or nearly so, and in a comfortable position. Little difficulty was encountered from movements of the arm, and when they did occur they were readily recognized as such on the tracing. The temperature of the room was usually between $21^{\circ}$ and $23^{\circ} \mathrm{C}$. and constant within $1^{\circ}$. Emotional distractions and noise were excluded as much as possible.

Routinely, the plethysmograph temperature was started at $22^{\circ}$ to $23^{\circ} \mathrm{C}$. and readings taken here and at $30^{\circ}$ and $42^{\circ} \mathrm{C}$. In many cases readings were also made at $36^{\circ}$. At each temperature, determinations of blood flow were made at frequent intervals until a constant level was reached. This usually took from 20 to 30 minutes, the longest time being required at the lowest and at the highest temperature. This was done as described by Freeman (12) by inflating the cuff to a pressure of about $60 \mathrm{~mm}$. $\mathrm{Hg}$ and taking a short tracing of the rate of increase of hand volume.

When the blood flow had become constant the tone of the veins was measured by determining the increase in volume of the hand produced by a cuff pressure of $10 \mathrm{~mm}$. Hg. The cuff pressure was then increased by consecutive amounts of $10 \mathrm{~mm} . \mathrm{Hg}$ up to 40 or $50 \mathrm{~mm}$. $\mathrm{Hg}$, and the change in hand volume found at each pressure. About 15 to 20 seconds were allowed at each pressure for a relatively constant volume level to be reached. This procedure was always repeated three or more times and the results averaged. The increments in volume were then calculated in cubic centimeters per liter of total hand volume, and plotted against the increments in cuff pressure. Since it was found that the volume in- crease occurring when the cuff was raised to $20 \mathrm{~mm}$. $\mathrm{Hg}$ was also an index of the tone of the vessels, it was frequently determined because this procedure took little time and produced little change in the experimental conditions.

In order to measure the reflex reaction of the minute vessels and veins to a painful stimulus, the patient was pinched. It was, of course, realized that there are many variable factors in a stimulus of this sort, but the results proved to be reasonably constant. The pinch was performed on the upper arm of the hand being studied, as it was found that it made no difference which arm was stimulated. An attempt was made to give as uniform a stimulus as possible. Several such tests were usually made and the greatest change in volume taken. The test was done by raising the cuff pressure to $20 \mathrm{~mm}$. Hg and obtaining a constant level of hand volume. The patient was then pinched and with the cuff at the same pressure constantly, the hand volume recorded until the reaction was over. Evidence will be offered later in this paper showing that the decrease in volume recorded in such experiments is due primarily to constriction of the veins and minute vessels. Similar experiments were carried out in many instances with cuff pressures, varying from 0 to $80 \mathrm{~mm}$. $\mathrm{Hg}$.

At each temperature determinations of blood flow were made before and after each procedure. The response of the blood flow to pinch was always measured. Besides the variations in temperature, the effect of heating the leg in a special hot air heater was frequently tried. In this procedure the plethysmograph was kept at $30^{\circ}$ and the heater at about $45^{\circ}$ for one hour. The duration was shortened if the skin temperature of the opposite hand rose to $32^{\circ}$ or over (1). Sufficient time was always allowed between procedures to insure the return of normal conditions.

\section{MATERIAL}

Six normal subjects were studied intensively. Two were men and four were women. The ages varied from 18 to 50 years. Four other normals were studied at only one temperature in order to clarify specific points. In all cases the cardiovascular system was normal. Eleven patients with various pathological conditions related to the vascular system were investigated. Table II summarizes the diagnoses and chief findings in this group.

In all cases the condition of the heart and of the peripheral vascular system was assessed clinically. Frequently, the venous pressure was measured directly by the method of Moritz and Tabora (20) and was found to agree with the determinations made by means of the blood flow mentioned above. Most of the experiments were done in 
TABLE II

Abnormal subjects

\begin{tabular}{|c|c|c|c|c|c|c|c|c|c|c|c|c|}
\hline \multirow{4}{*}{ Patient } & \multirow{4}{*}{ Sex } & \multirow{4}{*}{ Age } & \multirow{4}{*}{$\begin{array}{c}\text { Blood } \\
\text { pressure }\end{array}$} & \multirow{4}{*}{$\begin{array}{l}\text { Ve- } \\
\text { nous } \\
\text { pres- } \\
\text { sure }\end{array}$} & \multirow{4}{*}{$\begin{array}{l}\text { Hand } \\
\text { vol- } \\
\text { ume }\end{array}$} & \multirow{4}{*}{ Diagnosis } & \multicolumn{5}{|c|}{$\begin{array}{l}\text { Increment of hand volume obtained by } \\
\text { raising cuff pressure from } 0 \text { to } 20 \mathrm{~mm} \text {. } 1 \mathrm{Hg}\end{array}$} & \multirow{2}{*}{$\begin{array}{c}\text { Decrease } \\
\text { in volume } \\
\text { with pinch. } \\
\text { Cuff } \\
\text { pressure } \\
20 \mathrm{~mm} . \mathrm{Hg} \\
\begin{array}{c}\text { Without } \\
\text { leg heater }\end{array}\end{array}$} \\
\hline & & & & & & & \multicolumn{4}{|c|}{ Without leg heater } & $\begin{array}{l}\text { With leg } \\
\text { heater }\end{array}$ & \\
\hline & & & & & & & \multicolumn{6}{|c|}{ Temperature of plethysmograph $\left({ }^{\circ}()\right.}$. \\
\hline & & & & & & & $23^{\circ}$ & $30^{\circ}$ & $36^{\circ}$ & $42^{\circ}$ & $30^{\circ}$ & $30^{\circ}$ \\
\hline \multirow{3}{*}{ E.L. } & \multirow[b]{2}{*}{$\mathrm{F}$} & \multirow{3}{*}{$\begin{array}{c}\text { years } \\
22\end{array}$} & \multirow{3}{*}{$\begin{array}{c}\mathrm{mm} . \\
\mathrm{Hg} \\
110 / 60\end{array}$} & \multirow{2}{*}{$\begin{array}{c}m m \\
\mathrm{Hg} \\
\mathrm{N}\end{array}$} & cc. & \multirow[b]{2}{*}{ Raynaud's disease } & $\begin{array}{l}\text { cc. per } \\
\text { liter of } \\
\text { hand } \\
\text { volume }\end{array}$ & $\begin{array}{l}\text { cc. per } \\
\text { liter of } \\
\text { hand } \\
\text { volume }\end{array}$ & $\begin{array}{l}\text { cc. per } \\
\text { liter of } \\
\text { hand } \\
\text { volume }\end{array}$ & $\begin{array}{l}\text { cc. per } \\
\text { liter of } \\
\text { hand } \\
\text { volume }\end{array}$ & $\begin{array}{l}\text { cc. per } \\
\text { liter of } \\
\text { hand } \\
\text { volume }\end{array}$ & $\begin{array}{l}\text { cc. per } \\
\text { liter of } \\
\text { hand } \\
\text { volume }\end{array}$ \\
\hline & & & & & 300 & & 0.2 & 0.5 & 4.2 & 6.7 & 10.0 & 0 \\
\hline & & & & & 250 & Postoperative & 6.0 & 14.7 & 22.5 & 18.4 & 13.3 & 0 \\
\hline B. & M & 48 & $110 / 70$ & $\mathrm{~N}$ & 580 & Acrocyanosis & 2.3 & 5.3 & & 4.4 & & 0.9 \\
\hline C.H. & $\mathrm{M}$ & 24 & $120 / 68$ & $\mathrm{~N}$ & 460 & Acrocyanosis & 3.8 & 11.1 & 15.3 & 12.9 & & 5.0 \\
\hline P.P. & M & 46 & $130 / 75$ & $\mathrm{~N}$ & 480 & $\begin{array}{l}\text { Postural hypotension } \\
\text { Syringobulbia }\end{array}$ & 2.2 & 9.6 & & 5.2 & & 5.0 \\
\hline M.T. & $\mathrm{F}$ & 68 & $164 / 72$ & $\mathrm{~N}$ & 300 & Postural hypotension & 0.3 & 0.8 & 3.3 & 4.2 & 6.4 & 0 \\
\hline R.H. & M & 31 & $90 / 60$ & $\mathrm{~N}$ & 365 & Transection upper dorsal cord & 0.5 & 3.5 & & 5.0 & & 1.0 \\
\hline W.H. & $\mathrm{M}$ & 60 & $130 / 80$ & 20 & 390 & $\begin{array}{l}\text { Arteriosclerotic heart disease } \\
\text { with decompensation }\end{array}$ & 1.7 & 2.2 & & 3.2 & & 1.5 \\
\hline J.B. & $\mathrm{F}$ & 35 & $190 / 130$ & N & 300 & Malignant hypertension & 1.0 & 2.4 & & 8.0 & 9.0 & 4.8 \\
\hline J.A. & M & 35 & $250 / 150$ & $\mathrm{~N}$ & 430 & Malignant hypertension & 0.7 & 3.0 & & 4.5 & & 0.7 \\
\hline I.M. & $\mathrm{M}$ & 44 & $105 / 70$ & $\mathrm{~N}$ & 400 & Cirrhosis of liver & 0.5 & 4.2 & & 7.5 & & 1.7 \\
\hline W.M. & M & 54 & & 7 & 470 & $\begin{array}{l}\text { Coronary thrombosis - } 4 \text { days } \\
\text { after (morphine) }\end{array}$ & & 3.4 & & 3.7 & & 0 \\
\hline & & & $100 / 60$ & $\mathrm{~N}$ & 500 & 10 days after & 1.4 & 1.7 & 3.7 & 3.0 & & 4.8 \\
\hline
\end{tabular}
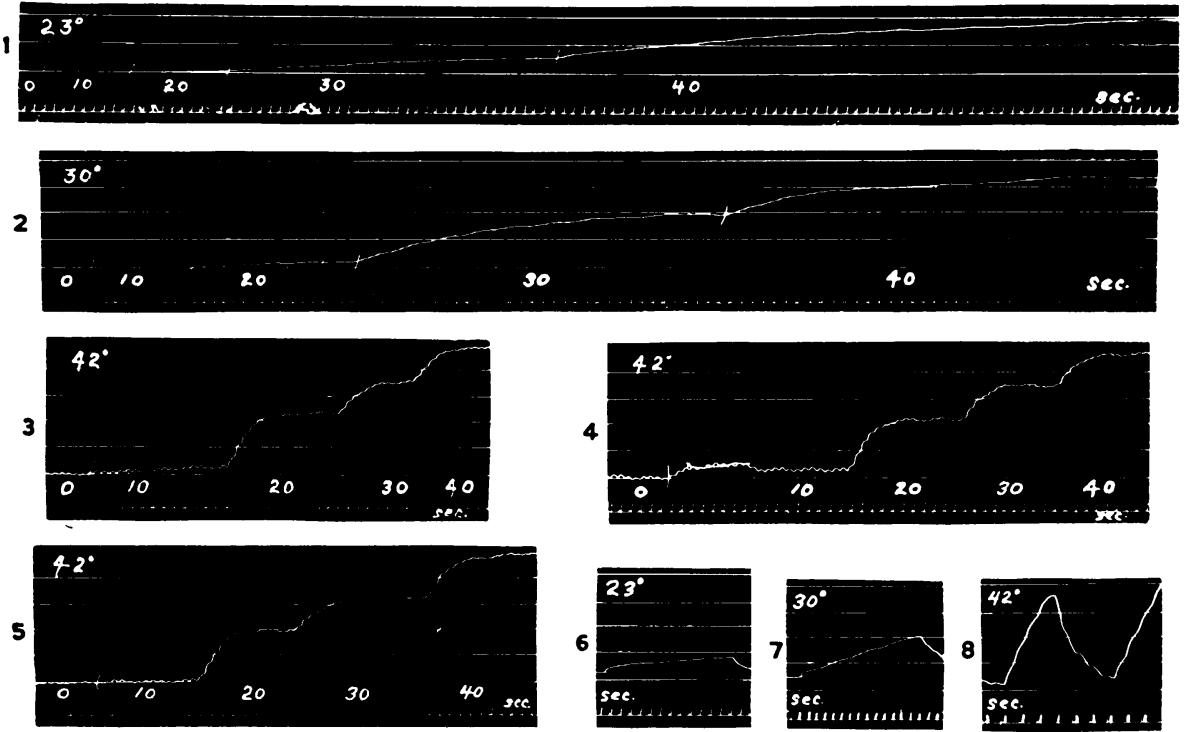

Fig. 1. Increment Curves from Normal Subject G. B.

Temperatures are those of the plethysmograph. Figures under curves represent cuff pressure in $\mathrm{mm}$. $\mathrm{Hg}$. The horizontal lines each represent $1 \mathrm{cc}$. of hand volume. Curves $6,7,8$ are curves of blood flow taken just before the increment curves at each temperature. Note that drum speed of Curve 8 is not the same as in the corresponding increment Curves 3, 4 and 5. Time markings all are one second. 
the laboratory, but where the patient was too sick to be moved the apparatus was taken to the ward.

\section{RESULTS}

Normals. As was to be expected, there was a great deal of variation in absolute values from subject to subject, but the general character of the results was the same. In a given patient under constant conditions repeated determinations agreed satisfactorily. Figure 1 illustrates typical tracings obtained from one of the normal subjects. It can be easily seen that the volume increases are less at low than at high temperatures. Blood flow curves (Numbers 6, 7 and 8) are included in order to show that the lack of increase in volume at $23^{\circ}$ and at $30^{\circ} \mathrm{C}$. is not due to an inadequate blood flow. In these curves of blood flow the cuff has been suddenly raised to $60 \mathrm{~mm}$. $\mathrm{Hg}$, and the rate of blood flow can be calculated from the slope and the time interval. Comparison of the blood flow curve with the corresponding volume tracing shows that in the latter, adequate time has been allowed at each cuff pressure for the volume to increase much more than it actually does. One must therefore conclude that the cause of the low volume increase at low temperatures lies in a failure of the veins to dilate, or in other words, in an increased venous tone. That this is really an increased physiological tone and not a permanent rigidity of the vessels is shown by their ability to dilate at higher temperatures.

Tracings 3, 4 and 5 , all at $42^{\circ} \mathrm{C}$., are included to show the agreement obtained between different determinations. At lower temperatures where spontaneous vasomotor changes are much more marked, the agreement is not so close. However, the variations between curves at a given temperature are always much less than between those at different temperatures.

Figure 2 is a graph of the increments of volume plotted against increments of cuff pressure from the same normal patient as Figure 1. The increase in volume in the 0 to $10 \mathrm{~mm}$. $\mathrm{Hg}$ increment in cuff pressure must be disregarded as, due to the existing pressure in the veins, it does not represent a change in venous pressure of $10 \mathrm{~mm}$. $\mathrm{Hg}$. It will be noted that when the hand is at $23^{\circ}$ the increments of volume are very small at first and

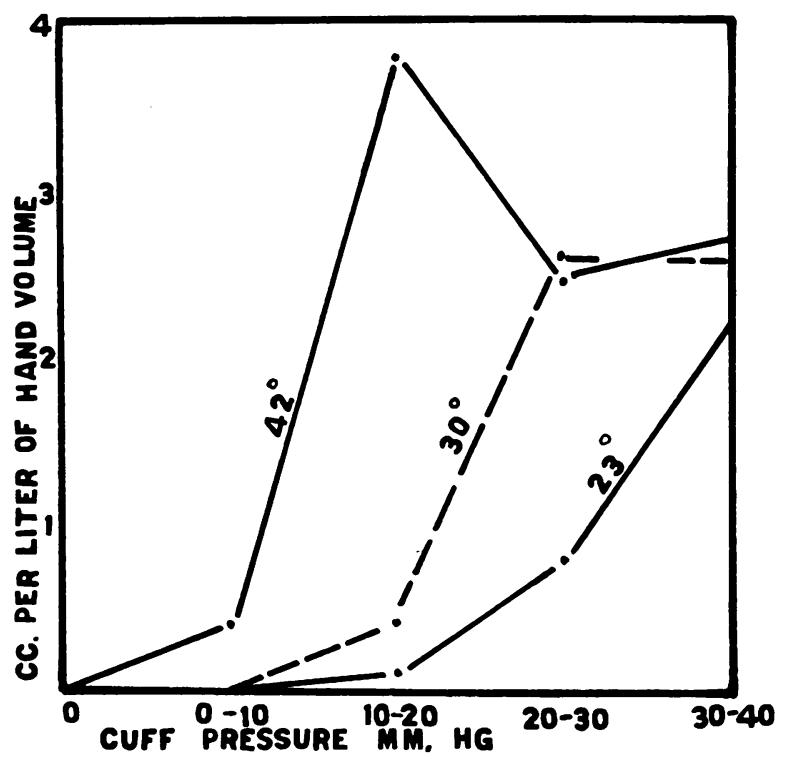

Fig. 2. Graph of Increments of Hand Volume Plotted against Increments of Cuff Pressure in Normal Subject G. B.

Figures computed from averages of all increment curves done on this patient. Temperatures are those of the plethysmograph.

then increase at higher cuff pressures, whereas at $42^{\circ}$ the first increment of volume is the greatest and the following ones decrease in value. The curve at $30^{\circ}$ is between the other two. It is readily seen from Figures 1 and 2 why a determination of the increase in volume when the cuff pressure is raised from 0 to $20 \mathrm{~mm}$. $\mathrm{Hg}$ gives a fair idea of the whole curve. These determinations remain quite constant under controlled conditions (Figure 3, Curve 4).

In all the normal subjects tested the curves responded to temperature in the above manner, showing greater increments of volume as the temperature was raised. Uniformly, the maximum increment of the volume occurred at a higher cuff pressure the lower the temperature. At $36^{\circ}$ and $42^{\circ}$ it was nearly always at the 10 to $20 \mathrm{~mm}$. $\mathrm{Hg}$ cuff pressure change, and at $23^{\circ}$ at the 30 to $40 \mathrm{~mm}$. $\mathrm{Hg}$ change or higher. The position at $30^{\circ}$ varied, sometimes being nearer that at $42^{\circ}$ and sometimes nearer that at $23^{\circ}$. Furthermore, the absolute value of the maximum increment of volume became greater as the temperature was raised. There was one exception to this last finding, namely, that occasionally the maximum incre- 

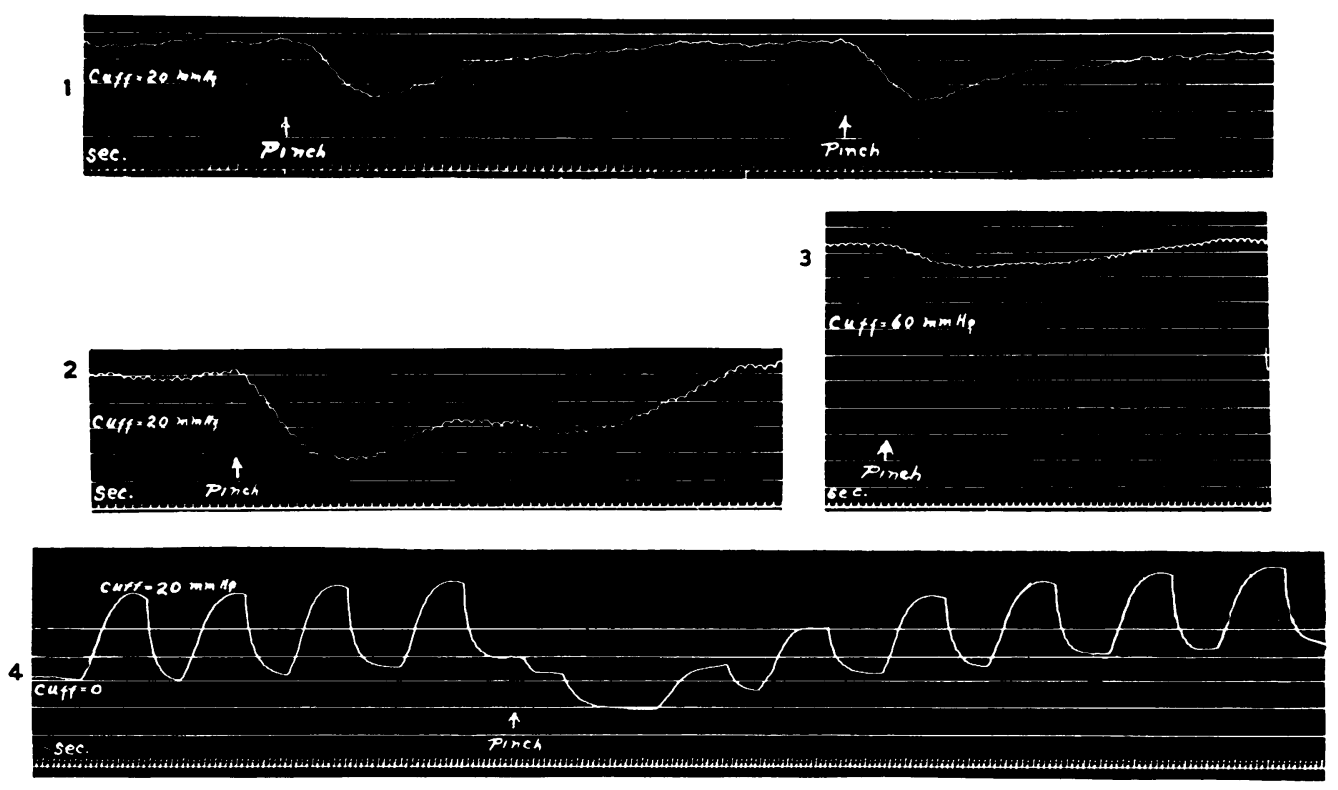

Fig. 3. Thif Reaction to Pixch.

Number 1 shows normal volume changes in Patient J. M. following pinch. Numbers 2 and 3 show reaction in normal patient with cuff pressure of 20 and $60 \mathrm{~mm}$. $\mathrm{Hg}$, respectively. Note the diminished fall in volume at the higher cuff pressure. Number 4 shows consecutive increments of volume due to raising the cuff from 0 to $20 \mathrm{~mm}$. $\mathrm{Hg}$ before and after a pinch. See text for further description. All horizontal lines represent $1 \mathrm{cc}$ of volume. Time markings are one second.

ment of volume was less at $42^{\circ}$ than at $36^{\circ}$. In these cases the arterioles were widely dilated at $42^{\circ}$, as shown by the rapid blood flow. Thus the capillary and venule pressure was probably so abnormally elevated, as Landis has found (15). that only the larger veins were affected by the cuff. This same phenomenon is regularly seen in measuring the increase in volume with a change in cuff pressure of 0 to $20 \mathrm{~mm}$. Hg during reactive hyperemia. The increase in volume is much less than during a control period, although the blood flow is very much greater.

Table I shows the increase in volume clue to a change in cuff pressure from 0 to $20 \mathrm{~mm}$. $\mathrm{Hg}$ in six of the normal subjects. These figures include the most extreme variations encountered.

Reflex dilatation. In order to determine the effect of reflex vasodilatation on the veins (21), the leg heater test was used on a limited number of patients. In all normal cases the resulting vasodilatation was essentially the same as that obtained by heating the hand to $36^{\circ}$ or $42^{\circ}$ in the plethysmograph. Often the dilatation was greater than that obtained by local heat. It is of interest that when the reflex dilatation of the arterioles was similarly tested using the blood flow as an index, it was found that local heat always caused a greater dilatation than heat applied to the leg. This last finding is not inconsistent with the results of Landis and (iiblon (21) since it must be remembered that in the experiments quoted here, the hand in which the blood flow was being measured was in a water bath at $30^{\circ}$ and not exposed to the air at room temperature.

The effect of pinching. When the effect of pinching was determined, the hand rolume in normals was found to diminish from 0 to $7 \mathrm{cc}$. per liter of hand volume with a mean of $1.9 \mathrm{cc}$. (Table I). The technical error of measurement ranged from 0.1 to 0.3 cc. per liter of hand volume. An increase in rolume following a pinch was never olsserved. This test was routinely done with a constant cuff pressure of 20 mm. Hg. The total hand volumes varied from $220 \mathrm{cc}$. to $510 \mathrm{cc}$. The diminution of volume began in 6 to 15 seconds, reached a minimumin in from 15 to 45 seconds and returned to the initial level in from 40 seconds to 3 minutes. Occasion- 
ally, a secondary drop was seen at about 40 seconds (Figure 3, tracing 2). The regularity and rapidity with which this change in volume occurred indicated that it was vascular in origin. In a given patient, under the same conditions, the experiment could be repeated a number of times with satisfactory agreement in results. Figure 3, tracing 1 , shows typical curves with unusually good agreement. The fall was usually greatest at $30^{\circ}$. Frequently it was 0 at $23^{\circ}$ when the blood flow and increment curves showed marked vasoconstriction. Likewise at $42^{\circ}$ the reaction was always diminished and often absent. It was noted that fear and various other psychic stimuli gave the same type of reaction as pinching.

In view of the fact that the arterioles were known to constrict, as measured by the blood flow, following a pinch (22), it was necessary to show that the diminution in volume was not due to arteriolar constriction. There are three reasons for considering that the diminution in volume is venous in origin. In the first place, several patients were found who showed a good slowing of blood flow with pinch, but not over $0.1 \mathrm{cc}$. drop in volume. In general, there was no definite correlation between these two phenomena from patient to patient.

In the second place, it was found that the amount of drop was directly related to the cuff pressure. The greatest fall in volume occurred without cuff pressure, and only a small drop occurred with a cuff pressure of 60 or $80 \mathrm{~mm}$. Hg (Figures 3 and 4 ). This might be expected if constriction of the capillaries and veins is the cause, but should not be true if the decrease in volume is due to the arterioles, as their normal intravascular pressure is at least $40 \mathrm{~mm}$. $\mathrm{Hg}$ and usually 50 to $60 \mathrm{~mm}$. $\mathrm{Hg}$ (15).

Finally, venous tone has been found to increase following a pinch, using as an index the increment of volume when the cuff pressure is raised from 0 to $20 \mathrm{~mm}$. Hg. Tracing 4 in Figure 3 shows a series of volume increments of this sort before and after a pinch. It will be noted that the height of the curves remains quite constant in spite of a slight rise in the base line due to a change in the basal volume of the hand when the cuff pressure is zero. Following the pinch the basal volume of the hand falls, reaching a mini-

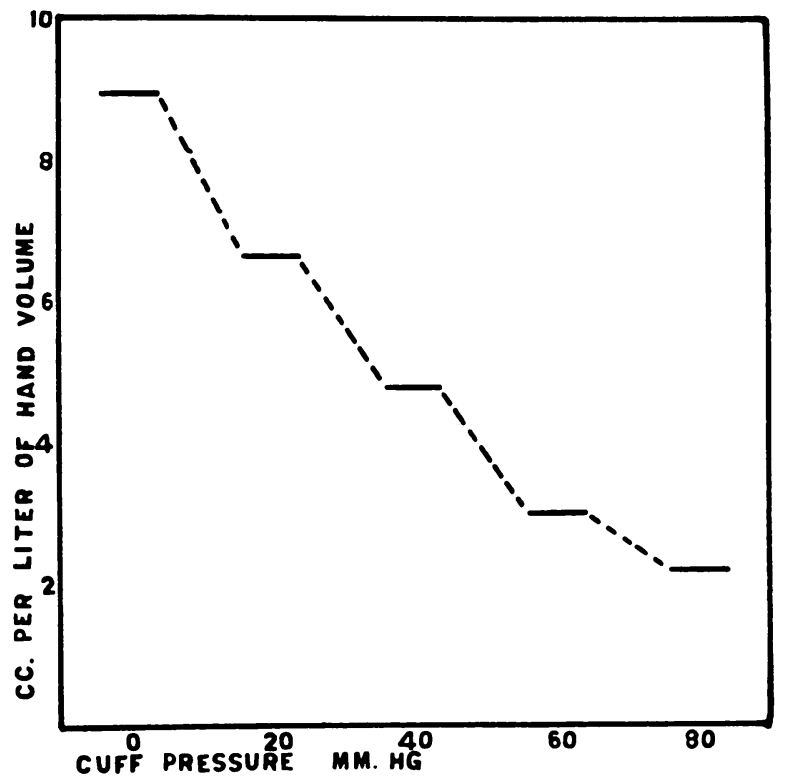

Fig. 4. Graph Showing Fall in Volume of Hand with Pinch at Different Cuff Pressures in Normal Patient.

Four to six determinations were made at each cuff pressure and averaged.

mum in 15 seconds (the fall is interrupted by a short plateau caused by a temporary application of cuff pressure). Curves of volume increment done at the minimum level show a 50 per cent decrease in height and then gradually return to their original level, as the basal volume of the hand rises. These observations were repeated a number of times with similar results. This experiment is very strong evidence that venous and capillary tone is increased following a pinch.

It should also be mentioned that the observations made on the pathological cases, especially those with acrocyanosis, are entirely consistent with the above findings. Furthermore, the fact that the pinch reaction is absent, or nearly so, at low temperatures when the vessels are already constricted and at $42^{\circ}$ when the vessels are strongly dilated, is exactly what would be expected.

Thus it can be concluded that at least a large portion of the diminution in volume following a pinch is due to constriction of the capillaries, venules and veins alone or in combination. Which of these three types of vessels is involved, it is impossible to say. Undoubtedly a small part of the fall is due to arteriolar constriction. 
Subjects with pathological conditions. A general summary of the findings in the 12 abnormal patients studied is presented in Table II. Lack of space prevents more than a presentation of the salient points. The most important case studied, from the physiological point of view, was that of a girl of 22 years with Raynaud's disease. The left hand was tested before and six days after alcohol injection of the stellate and upper two dorsal sympathetic ganglia of the ipsilateral side.

Figure 5 shows the increase in volume produced by $20 \mathrm{~mm}$. $\mathrm{Hg}$ cuff pressure at different tempera-

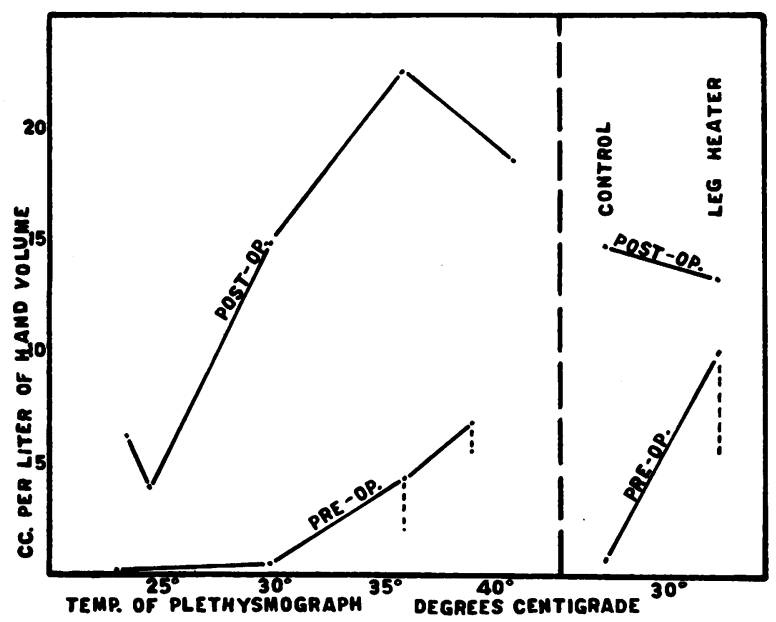

Fig. 5. Graph of the Increments of Volume Obtained by Raising the Cuff Pressure from 0 to 20 ma. Hg in Patient E. L. with Raynaud's Disease.

Determinations made before and after alcohol injection of stellate and upper dorsal sympathetic ganglia. At right is the effect of a leg heater applied for 1 hour at $45^{\circ}$ with the hand temperature at $30^{\circ}$. Dotted lines represent the fall of volume with pinching. No fall occurred preoperatively at $23^{\circ}$ or $30^{\circ}$ and none postoperatively at any time.

tures and the decrease in volume with pinch before and after the operation, respectively. The pinch reaction is abolished postoperatively. It will be seen that the increases in volume are very large, indicating that the veins are extremely atonic. On the right is shown the reaction to the leg heater which was completely abolished, as might be expected (21). The blood flow in this case was greatly increased by the operation, and the fall in blood flow following pinch was abolished. Wiedhopf (23) has made a somewhat similar observation by noting the decrease in hand volume when the other hand is exposed to very low temperature. He found that novocainization of the median, radial and ulnar nerves abolished the reaction. He attributed the fall in volume to arteriolar constriction, however.

Two patients with acrocyanosis were investigated. In both cases the blood flow was nearly absent at $23^{\circ}$ but high at $42^{\circ}$. The reaction of the blood flow to pinch was essentially normal. One of the two showed venous increment curves of the relaxed type at all temperatures (Figure 6). Furthermore, the pinch test produced only a

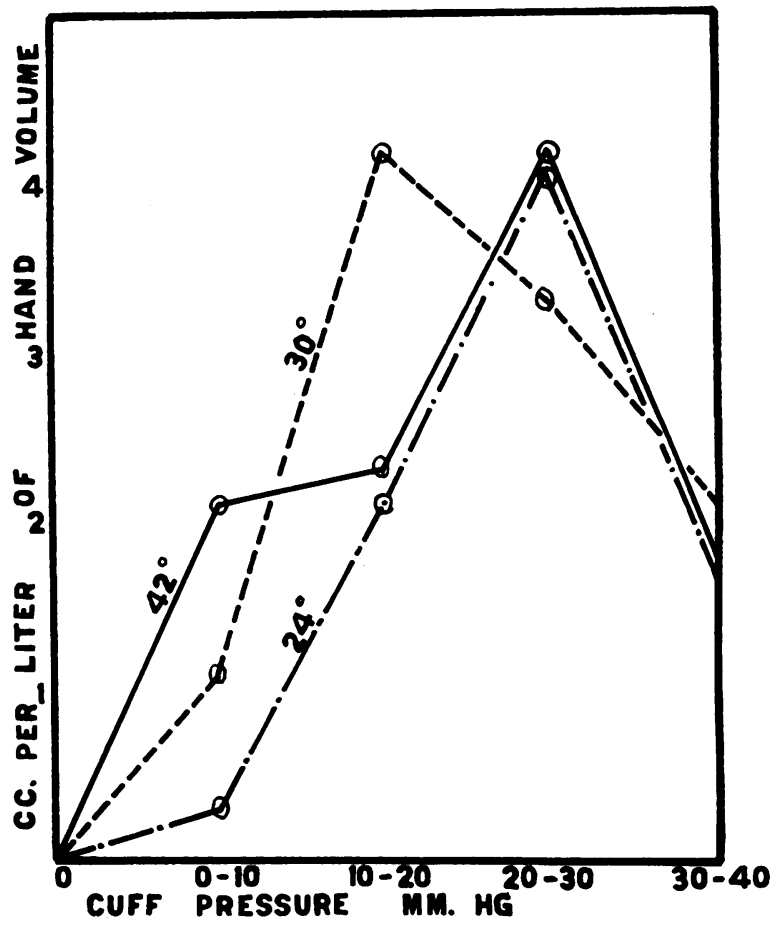

Fig. 6. Graph of Volume Increments Plotted against Increments of Cuff Pressure of Patient B. With ACROCYanosis.

Comparison with Figure 2 shows that venous tone is markedly reduced at low temperatures.

very slight diminution in volume. This suggests that the veins and capillaries of this patient were relaxed even at low temperatures and that reflex venoconstriction was practically absent. From the other patient the remarkably high increment curves shown in Figure 7 were obtained. Although at $23^{\circ}$ the maximum increment of the volume occurs at 30 to $40 \mathrm{~mm}$. $\mathrm{Hg}$ cuff pressure, the actual volume of the increments is very large. 


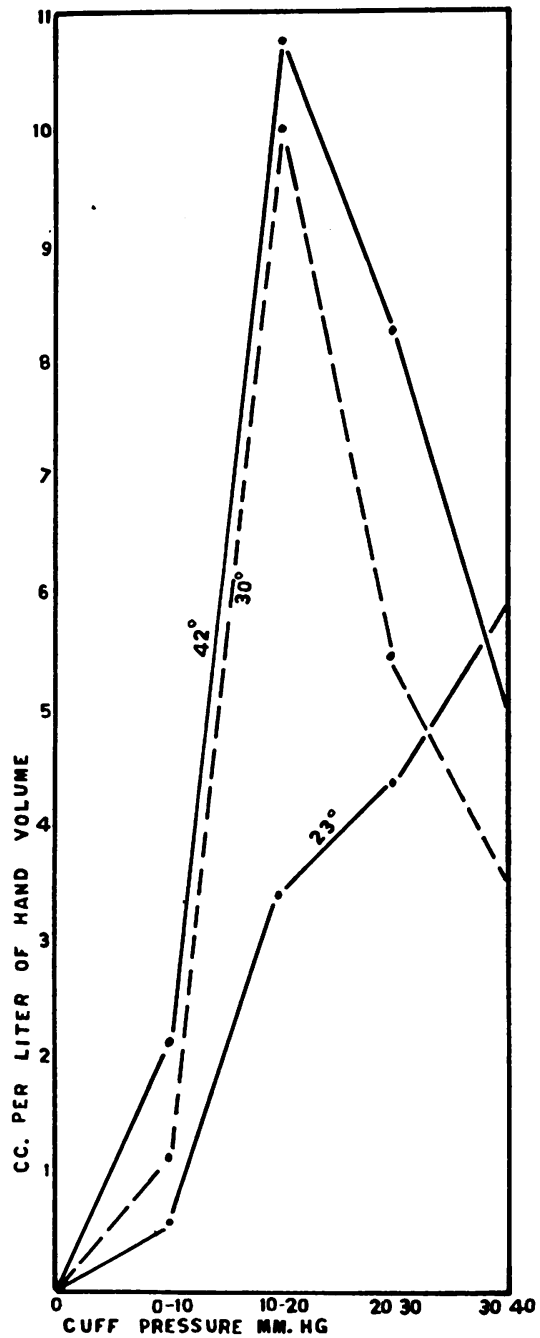

Fig. 7. Graph of Increments of Volume Plotted against Increments of Cuff Pressure of Patient C. H. with Acrocyanosis.

Note the abnormal height of these curves.

The exact significance of these very high increases in volume is not clear. The figures are nearly as high as those obtained in the denervated hand of the patient with Raynaud's disease. They may indicate moderate relaxation of the veins and capillaries or may be due to a greater vascular bed than normal. The pinch test in this case was normal.

Two patients with postural hypotension of severe degree were examined. In one case secondary to syringomyelia no abnormalities were found. In the other case, without obvious cause for her condition except for her age of 64 , there was practically complete absence of change in either arterioles or veins with pinching. Otherwise the venous tone was normal.

One patient with transection of the cord in the region of the fourth dorsal segment and with hematomyelia involving a number of higher segments was studied. The palms of his hands were red and became cyanotic when hung over the side of the bed. He had been in bed for one year. With low temperatures the venous tone was only fair. Only a slight fall in volume could be obtained on pinching. These findings suggest damage of the sympathetic nerve supply to his hand.

In one case of arteriosclerotic heart disease and congestive failure in a man of 51 the findings were of some interest. His venous pressure was 18 $\mathrm{mm}$. Hg by direct measurement, so that the 20 to $30 \mathrm{~mm} . \mathrm{Hg}$ increment is the first one of any value. The increment curves were all rather flat, but the maximum volume increment occurred at a lower cuff pressure with higher temperatures (Figure 8 ). This suggests that venous tone was

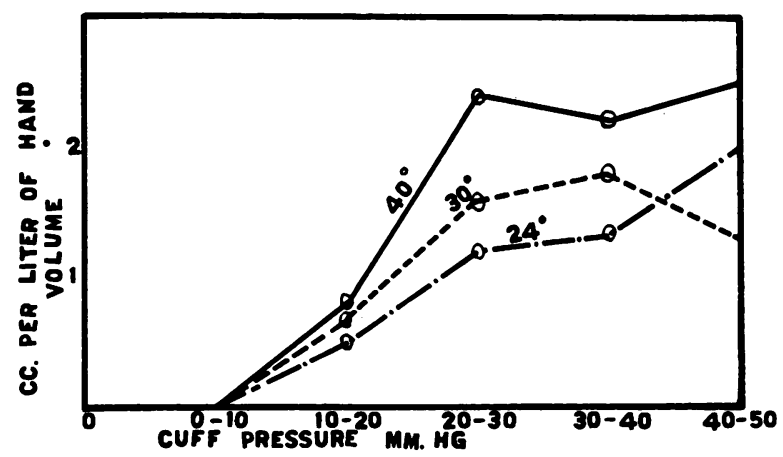

Fig. 8. Graph of Increments of Volume of Patient W. H. with Decompensated Arteriosclerotic Heart Disease.

Venous pressure $18 \mathrm{~mm}$. Hg. The 10 to $20 \mathrm{~mm}$. $\mathrm{Hg}$ increments must be disregarded because of elevated venous pressure.

still present in spite of chronic increased venous pressure.

In the remaining patients the findings were not remarkable. It is interesting that two patients with malignant hypertension had no abnormalities. One was colored and his racial threshold to pain may explain the poor pinch test. One case of coronary thrombosis was tested four and ten days after the onset. During the first test he was 
under morphine which may explain the absence of a reaction to pinch and the absence of venous tone at all temperatures. Both of these findings were normal 10 days after his thrombosis.

\section{DISCUSSION}

The validity of the method here described for measuring the tone of the veins, venules and capillaries is not open to direct proof by any means available to the author. It is recognized that the arguments and proof offered are indirect. But, because all of the experiments done were confirmatory and because of the consistency of the results it is believed that the method, when properly executed, is valid and qualitatively reliable.

Several objections naturally arise which should be answered. It may be said that the increasing increments of volume at low temperatures are due to a progressive reactive hyperemia caused by the prolonged increase in venous pressure (1). This is easily disproven by applying the cuff at $40 \mathrm{~mm}$. $\mathrm{Hg}$, the maximum pressure used, for an equal length of time, usually 1 to 2 minutes. In spite of a greater venous pressure for the whole time than during the increment curves only a very slight increase in volume occurs above the initial rise. The factor of edema formation is rendered negligible by not using cuff pressures over $40 \mathrm{~mm}$. $\mathrm{Hg}$ in the increment curves. From Landis' (24) results, it can be seen that with the cuff pressures and time intervals used, edema formation is not significant.

The increment curves may be thought to represent the extent of vessels involved rather than their elasticity. But if this were true, then all of the increments should be diminished at higher temperatures because Landis (15) has shown that the capillary pressure is increased under these conditions. If the very small volume increments found in some patients at low temperatures were due to markedly increased capillary and venule pressure as was suggested by Hough and Ballantyne (25) which is very unlikely from Landis: (15) data, they still would indicate marked venous constriction.

The nature of the tonus or resistance to stretch that has been measured cannot be elucidated. The change in the resistance to stretch with temperature may be due to an action of the latter on the elastic elements of the vessels and not on the muscles. The change in resistance to stretch produced by pinching, however, must be muscular in origin as nervous stimulation can hardly affect the non-muscular tissue. Winton. (26) in a recent paper finds that smooth muscle tonus is composed of an elastic, a viscous elastic, and viscous component. At least the first and last are affected by temperature. Therefore, we can only conclude that physiologically significant changes in the resistance to stretch of the veins do occur in response to temperature and pain although the exact mechanism is obscure.

The demonstration in the whole human hand of venous reflex constriction and the presence of tone in relation to temperature is of considerable importance. In studies of the whole peripheral circulation these factors have not been taken into proper consideration, largely because of lack of exact knowledge concerning them and lack of methods for their investigation. Henderson (8), Fleisch (7) and Dale (4) have pointed out their importance.

Since only a few diseases and a few patients with each disease have so far been investigated by this technique, conclusions must necessarily be tentative. The finding in acrocyanosis of relaxed veins at a low temperature with a very slow blood flow explains both the apparent swelling and the cyanosis. This is confirmatory of the studies of Lewis and Landis (27) on the subject. In one of the patients with postural hypotension, the absence of a reaction to pinch of the veins may indicate poor or absent reflexes to these vessels. The fall in blood pressure on standing in her case may be in part due to stagnation of blood in the veins and capillaries. It is also of interest that evidence of venous tone was presented in a patient with congestive failure and increased venous pressure. The prominence of the veins in such patients is apt to lead to an erroneous assumption that they are rather completely dilated. The absence of significant abnormalities in two cases of severe malignant hypertension suggests that there is no involvement of the veins, venules and capillaries in this condition. This is confirmatory of previous studies by Weiss and Ellis (28).

One further finding may be of importance, 
namely, the abolition of the pinch reaction by local heat. This same phenomenon is seen in observations on the reaction of the blood flow to pinching. It is of interest that reflex vasomotor dilatation by the leg heater increases the reaction to pinch. Thus local heat seems to be a potent vasodilator and can overcome reflex constriction.

\section{CONCLUSIONS}

1. A method has been presented for measuring the tone of the veins, venules and capillaries of the human hand as a whole and for determining the reflex reaction of these vessels to a noxious stimulus, a pinch.

2. It has been shown that the tone of these vessels normally increases with cold and reflexly increases with the pinch. Their tone decreases with local heat and reflexly with heat to the leg.

3. Evidence has been presented that the decrease in hand volume following a pinch is actually due chiefly to a reflex constriction of the veins, venules and capillaries.

4. In two cases of acrocyanosis an abnormal absence of tone of the veins, venules and capillaries has been found. Coupled with an unusually slow blood flow at low temperature, this finding can explain the clinical picture.

5. In two cases of severe malignant hypertension, no significant abnormalities were found by this technique.

\section{BIBLIOGRAPHY}

1. Lewis, T., The Blood Vessels of the Human Skin and their Responses. Shaw, London, 1927.

2. McDowall, R. J. S., The nervous control of the blood vessels. Physiol. Rev., 1935, 15, 98.

3. Krogh, A., The Anatomy and Physiology of the Capillaries. Yale University Press, New Haven, 1922.

4. Dale, H. H., Capillary poisons and shock. Bull. Johns Hopkins Hosp., 1920, 31, 257.

5. Fleisch, A., Venomotorenzentrum und Venenreflexe. I and III. Arch. f. d. ges. Physiol., 1930, 225, 26; 1931, 228, 399.

6. Donegan, J. F., The physiology of the veins. J. Physiol., 1921, 55, 226.

7. Fleisch, A., Neuere Ergebnisse über Venenfunktion. Schweiz. med. Jahrbuch., Bemo Schwabe \& Co., Basl, 1931.

8. Henderson, Y., The volume of the circulation and its regulation by the venopressor mechanism. J. A. M. A., 1931, 97, 1265.
9. Capps, R. B., Unpublished observations.

10. Hewlett, A. W., and Zwaluwenburg, J. G. van, The rate of blood flow in the arm. Heart, 1909, 1, 87.

11. Hewlett, A. W., The effect of room temperature upon the blood flow in the arm, with a few observations on the effect of fever. Heart, 1911, 2, 230.

12. Freeman, N. E., The effect of temperature on the rate of blood flow in the normal and in the sympathectomized hand. Am. J. Physiol., 1935, 113, 384.

13. Drury, A. N. and Jones, N. W., Observations upon the rate at which edema forms when the veins of the human limb are congested. Heart, 1927, $14,55$.

14. Lewis, T., The force exerted by the minute vessels of the skin in contracting. Heart, 1924, 11, 109.

15. Landis, E. M., Capillary pressure and capillary permeability. Physiol. Rev., 1934, 14, 404.

16. Clark, Janet H., The elasticity of veins. Am. J. Physiol., 1933, 105, 418.

17. Evans, C. L., The physiology of plain muscle. Physiol. Rev., 1926, 6, 358.

18. MacWilliams, J. A., On the properties of the arterial and venous walls. Proc. Roy. Soc. Med., 1902, 70, 109.

19. Kesson, J. E., The elasticity of the hollow viscera. Quart. J. Exper. Physiol., 1913, 6, 355.

20. Moritz, F. and von Tabora, D., Uber eine Methode, beim Menschen den Druck in oberflächlichen Venen exakt zu bestimmen. Deutsches Arch. f. klin. Med., 1910, 98, 475.

21. Landis, E. M. and Gibbon, J. H., Jr., A simple method of producing vasodilatation in the lower extremities with reference to its usefulness in studies of peripheral vascular disease. Arch. Int. Med., 1933, 52, 785.

22. Capps, R. B., and Ferris, E. B., Jr. (To be published).

23. Wiedhopf, O., Experimentelle Untersuchungen über die Wirkung der periarteriellen Sympathectomie und der Nervenvereisung auf die Gafässe der Extremitäten. Beitr. z. klin. Chir., 1924, 130, 399.

24. Landis, E. M., and Gibbon, J. H., Jr., The effects of temperature and of tissue pressure on the movement of fluid through the human capillary wall. J. Clin. Invest., 1933, 12, 105.

25. Hough, T., and Ballantyne, B., Preliminary note on the effects of changes in external temperature on the circulation of blood in the skin. J. Med. Sc., Boston, 1899, 3, 330.

26. Winton, F. R., Tonus in mammalian unstriated muscle. I. J. Physiol., 1930, 69, 393.

27. Lewis, T., and Landis, E. M., Observations upon the vascular mechanism in acrocyanosis. Heart, 1929$31,15,229$.

28. Weiss, S., and Ellis, L. B., The quantitative aspects and dynamics of the circulatory mechanisms in arterial hypertension. Am. Heart J., 1930, 5, 448. 